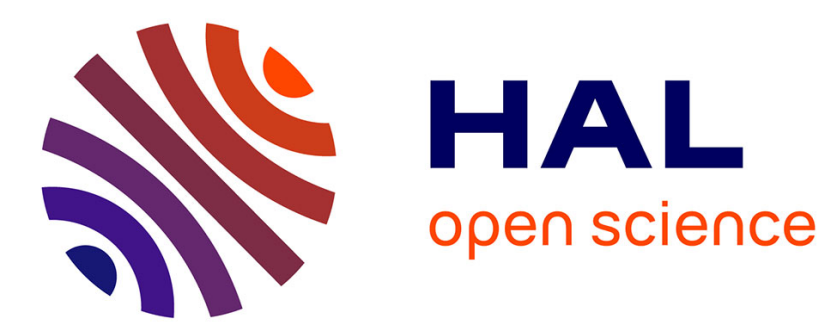

\title{
Orienting insecticide research in the tropics to meet the sustainable development goals
}

Quentin Struelens, Pierre Silvie

\section{To cite this version:}

Quentin Struelens, Pierre Silvie. Orienting insecticide research in the tropics to meet the sustainable development goals. Current Opinion in Insect Science, 2020, 40, pp.24 - 30. 10.1016/j.cois.2020.05.015 . hal-03394527

\section{HAL Id: hal-03394527 \\ https://hal.science/hal-03394527}

Submitted on 22 Oct 2021

HAL is a multi-disciplinary open access archive for the deposit and dissemination of scientific research documents, whether they are published or not. The documents may come from teaching and research institutions in France or abroad, or from public or private research centers.
L'archive ouverte pluridisciplinaire HAL, est destinée au dépôt et à la diffusion de documents scientifiques de niveau recherche, publiés ou non, émanant des établissements d'enseignement et de recherche français ou étrangers, des laboratoires publics ou privés. 


\section{Journal Pre-proof}

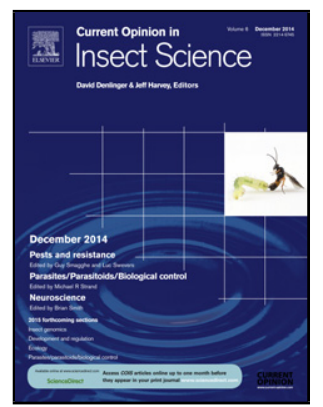

Orienting insecticide research in the tropics to meet the sustainable development goals

Quentin Struelens (Conceptualization) (Methodology) (Formal analysis) (Investigation) (Data curation) (Writing - original draft) (Writing - review and editing), Pierre Silvie (Conceptualization) (Methodology) (Investigation) (Writing - review and editing) (Supervision)

PII: S2214-5745(20)30079-1

DOI: https://doi.org/10.1016/j.cois.2020.05.015

Reference: COIS 704

To appear in: Current Opinion in Insect Science

Please cite this article as: Struelens $Q$, Silvie P, Orienting insecticide research in the tropics to meet the sustainable development goals, Current Opinion in Insect Science (2020), doi: https://doi.org/10.1016/j.cois.2020.05.015

This is a PDF file of an article that has undergone enhancements after acceptance, such as the addition of a cover page and metadata, and formatting for readability, but it is not yet the definitive version of record. This version will undergo additional copyediting, typesetting and review before it is published in its final form, but we are providing this version to give early visibility of the article. Please note that, during the production process, errors may be discovered which could affect the content, and all legal disclaimers that apply to the journal pertain.

(C) 2020 Published by Elsevier. 


\title{
Orienting insecticide research in the tropics to meet the sustainable development goals
}

\author{
Quentin Struelens ${ }^{1,2, *}$ and Pierre Silvie ${ }^{3,4}$
}

\begin{abstract}
${ }^{1}$ Museum National d'Histoire Naturelle, Sorbonne Universités, Paris, France
${ }^{2}$ Institut de Recherche pour le Développement, Centre d'Écologie Fonctionnelle et Évolutive, UMR 5175, CNRS, Université de Montpellier, Université Paul Valéry Montpellier, EPHE, IRD, Montpellier, France

3IRD, UMR IPME, 34AA001, Montpellier, France

${ }^{4}$ CIRAD, UPR AÏDA, BP 34398 Cedex 5, Montpellier, France

${ }^{*}$ Corresponding author:

Quentin Struelens, Muséum national d'Histoire naturelle, Sorbonne Universités 57 rue Cuvier, 75005 Paris, France, E-mail: quentin.struelens@gmail.com
\end{abstract}

\section{Highlights}

- Five topics of tropical insecticide research were identified as particularly sustainable

- We discussed drivers impacting these research topics in the tropics

- Studies combining different topics and interdisciplinary research were highlighted

\section{Abstract}

Tropical cropping systems are highly dependent on synthetic insecticides, which generates sustainability issues. We performed a bibliometric analysis of the current insecticide literature (2017-2019) and used the Sustainable Development Goals roadmap to identify research topics in insecticide research that should be promoted to attain sustainable cropping systems. Bioinsecticides and integrated pest management were identified as potential substitutes for synthetic insecticides while insecticide contamination, degradation and impacts on non-target organisms were pinpointed as topics with the potential to lessen detrimental effects of synthetic insecticides. We also highlighted how peculiarities specific to the tropics (tropical climate, high biodiversity, strong traditional knowledge, insecticide 
regulations, lack of local scientific data, and farmer training through extension services) affect the identified research topics and why they should be taken into account. We finally suggest to combine the identified research topics in order to promote research synergies across disciplines.

\section{Introduction}

Tropical cropping systems are highly dependent on synthetic insecticides for pest control, especially in commercial crops [1-3]. Insecticides can affect human health [4], persist in the soil, pollute water sources [5], harm non-target organisms such as pollinators and soil microorganisms [6] and induce resistance in targeted pests [7]. Pest management based only on chemical insecticides is therefore unsustainable. The 17 Sustainable Development Goals (SDG) adopted in 2015 by the United Nations offer a roadmap to attain a sustainable world by 2030. This roadmap is made of 169 specific targets (full list available at https://sustainabledevelopment.un.org/topics/sustainabledevelopmentgoals). The SDG can be used as a framework to orient insecticide research towards a more sustainable pest management. This is especially true in less-developed tropical countries where major challenges for zero hunger (SGD 2) and good health and well-being (SDG 3) remain to be addressed [8].

In this study, we performed a bibliometric analysis to identify current and promising insecticide research topics in tropical countries that could be fostered to meet the SDG. To do so: i) we searched the literature (Web of Science) on insecticide research (query = "insecticide*") for the last three years (20172019) from tropical countries, ii) we screened the titles and abstracts of one fifth ( $n=439$ ) of randomly selected articles (out of 2212) to identify the major research topics and subtopics, iii) we classified the remaining articles using a supervised classification model based on the most frequent keywords for each topic, and iv) we aligned subjectively each research topic with relevant specific targets among the 17 SDG (see detailed methodology in Supplementary Material). Finally, we selected the five most SDGaligned research topics and discussed their relevance under the abiotic, biotic and human-related peculiarities of the tropics. In this context, we proposed future research directions to be fostered in order to attain a more sustainable pest management in the tropics. Note that we focused our discussion on the use of insecticides in cropping systems, even though animal and human health were also part of the literature survey and identified topics. 


\section{Insecticide research topics to be promoted to meet the SDG}

Our literature survey revealed 2212 articles published across 59 tropical countries for the period 2017-2019. We identified 11 research topics during our screening encompassing a total of 41 subtopics (Table 1), which were aligned with 11 out of the 17 SDG (Figure 1). We selected five topics as being key for achieving SDG because they were in line with at least 7 SDG (Figure 1, in blue): i) contamination by insecticides, ii) insecticide degradation and bioremediation, iii) insecticide impacts on non-target organisms, iv) integrated pest management, and v) bioinsecticides. The selected research topics fell into two main categories: they were either related to insecticide fate and impact on the environment or related to alternative less-harmful solutions to synthetic insecticides.

Contamination by insecticides, insecticide degradation and bioremediation, and insecticide impacts on non-target organisms explore the fate and impact of insecticides on the environment. Contamination by insecticides is a worldwide issue occurring when insecticide compounds accumulate within water, soil, or plant tissues (including residues in crop products). However, a contamination event is limited in time because these pesticide compounds will ultimately degrade naturally through both abiotic (e.g. volatilization, oxidation) and biotic (e.g. enzymatic degradation) pathways [9]. Restoration strategies (e.g. bioremediation) have been developed to strengthen the natural degradation in order to remove insecticide residues from contaminated substrates [10,11] (SDG 6, 14 \& 15). Nevertheless, during the window of time when insecticides are not yet degraded (from days to years depending on the compound and abiotic conditions), non-target organisms (e.g. soil biota, natural enemies, fishes) can be exposed to these compounds through many exposure routes (inhalation, ingestion,...) that can be fatal depending on the dose [12], resulting in potential disruption of related ecosystem services (SDG 14 \& 15). We believe that more research on contamination and degradation of insecticides, along with their impacts on non-target organisms will help to promote access to clean water free of chemicals (SDG6), reduce food and water contaminations to support good health (SDG3), encourage responsible consumption and production of insecticides (SDG12) and reduce impact on both aquatic (SDG14) and terrestrial (SDG15) biodiversity (Figure 1).

Integrated pest management and biopesticides explore the alternative solutions to synthetic insecticides. Indeed, the unsustainable nature of synthetic insecticide use, which led researchers to develop the concept, paradigm today, of integrated pest management (IPM), "a decision support system for the selection and use of pest control tactics, singly or harmoniously coordinated into a management strategy, based on cost/benefit analyses that take into account the interests of and impacts on 
producers, society and the environment" [13]. IPM proposes a combination of rational use of synthetic insecticide [14], with other solutions such as companion plants that can act as repellent (push), trap crops that are attractive to the pest (pull), or nectar-provisioning plants that attract natural enemies. Another alternative to synthetic insecticides, sometimes included within IPM, are bioinsecticides. These products are defensive chemical compounds naturally produced by microorganisms, fungi, or plants that are mass-produced and delivered to farmers for pest control [15]. The majority of these natural products are usually less persistent than synthetic insecticides, which reduces environmental contamination, and are less harmful to non-target organisms [16]. Bioinsecticides, especially the phytochemicals, can be produced locally [17], thereby increasing farmers' resilience (SDG 11) and reducing pest management costs (SDG 1). Finally, a landscape approach to ecosystem services (including natural pest control) goes beyond IPM in scope and scale, with promising results for pest management [18].

An additional way to promote more sustainable cropping systems consists in combining several research topics within the same approach. For example, Amoabeng et al (2019) [ref. 19] identified plants with the potential to control pests through both bioinsecticide development and natural enemy enhancement. Another study explores the combined effect of biochar and earthworms on both insecticide bioremediation and carbon sequestration [20]. These combined research topics are aligned with a more diverse set of SDG while keeping the cost of research unchanged.

We acknowledge a few limits to our approach. First, topic alignments with SDG only reflect our opinions that depend on our experiences and would have been different if other or more views were included. Second, our classification model showed a moderate accuracy (Kappa score of 0.6), which implies that the number of papers within each category should be considered with caution. Finally, we may have missed rare research topics because we decided to use a subsample of papers for topic definition.

\section{Tropics-specific drivers affecting insecticide research}

Even though we believe that research topics identified earlier should be promoted to attain more sustainable cropping systems, we also think that some tropics-specific drivers should be accounted for while executing research on these topics. Indeed, most environmental research has been carried out in temperate countries [21] and has then guided implementations in tropical countries. However, a number of peculiarities specific to the tropics that are usually not taken into account may lead to 
misleading results and recommendations leading to unsustainable use of insecticides in the tropical context.

\section{Tropical climate}

Tropical climate is usually warmer and more humid than temperate climate. These abiotic conditions promote pest population growth, which may result in more frequent pesticide applications [22]. At the same time, abiotic degradation of insecticides has been shown to be faster under tropical conditions, because of the higher temperature accelerating volatilization, chemical degradation, and microbial degradation $[22,23]$. At the same time, the high precipitation in tropical regions increases the risk of runoff and leaching of insecticide compounds [23]. However, even if higher degradation and leaching occur, a recent global assessment of insecticide concentrations in surface waters showed higher concentrations of several insecticides in tropical compared to temperate regions [24]. Additionally, whilst insecticides disperse, accumulate and degrade differently under tropical conditions, most of the recommendations in tropical countries are still based on research conducted in temperate regions, leading to potentially inadequate management $[23,25]$. Finally, climatic conditions are heterogeneous across the tropics with several ecosystems showing dryer conditions, such as the Tropical Andes, which increases the issue of transferring solutions developed for temperate systems to the tropics. We therefore stress the need for more research on insecticide contamination and degradation under tropical climate (SDG 9).

\section{High biodiversity and local traditional knowledge}

Tropical areas harbor the greatest biodiversity in the world along with a longstanding traditional knowledge held by local people. The high plant biodiversity offers a wide array of defensive chemicals from which bioinsecticides can be manufactured. For instance, neem oil, one of the oldest commercially available botanical insecticides is extracted from a tropical plant (Azadirachta indica, Meliaceae). Moreover, many by-products of local crops could readily be used as botanical insecticides (SDG 11 \& 12). For example the Andean Lupine (Lupinus mutabilis, Fabaceae) cultivated for human consumption needs to be washed before consumption to remove toxic alkaloids with potential insecticidal activity [26]. Farmers in less-developed tropical countries are also more interested in using botanical insecticides because of a longstanding traditional knowledge about local plants [17]. Botanical diversity also offers a vast pool from which companion plants can be selected for nectar provision or push-pull systems used in IPM. Therefore, biodiversity in the tropics has a strong potential to develop local sustainable solutions 
(SDG 9 \& 11) for pest control that could be guided by traditional knowledge through a partnership with local communities (SDG 17).

\section{Insecticide regulations}

In less-developed tropical countries, insecticide regulations are generally less constraining than in their temperate counterparts. This leads to both negative and positive consequences. On the one hand, more flexible regulations facilitate the development and commercialization of new bioinsecticides (SDG 9), whereas insecticide regulations are major barriers to commercialization in temperate countries $[17,27]$. On the other hand, many synthetic chemicals with longer persistence and higher toxicity for non-target organisms, including humans, have been banned in more developed countries but are still allowed in less-developed tropical countries [3]. Moreover, the standard non-target organisms used in toxicological studies to evaluate the environmental risks of insecticides generally originate from temperate countries [28]. For example, the honey bee (Apis mellifera, Hymenoptera) is used as a standard species to assess the impact of insecticides on pollinators, even though pollination in the tropics is highly dependent on stingless solitary bees that are not included in the evaluation [29]. A similar conclusion has been reached for non-target organisms participating in organic matter decomposition [25]. Therefore, studies on ecotoxicology of non-target organisms should evaluate the impacts on species present in the tropics instead of focusing on irrelevant temperate species. Overall, these examples stress the need to reduce inequalities of insecticide regulations between developed and less-developed countries (SDG 10).

\section{Extension services and training}

Agricultural extension services occupy a central role for diffusing pest control innovations, recommendations and training to farmers in less-developed countries [30,31]. Since the 1990's the type of extension organizations has shifted from mainly public agencies to a diversity organizations including NGO, farmers' associations or private extension services [31,32]. The increase in private extensions present several issues: i) smallholder farmers are not the main targets because of their low solvency $[31,33]$ and ii) private extensions usually have a dual role of merchandizing insecticides and advising farmers [30,34]. Extension personnel should be trained to propose alternative solutions to insecticides such as IPM, bioinsecticides or to provide taxonomic services. A global survey highlighted the "shortage of well-qualified expert and extensionists" about IPM in developing countries [35]. Local production of bioinsecticides could also be guided by extensionists, given that farmers spontaneously show interest on 
this topic [16]. A taxonomic service offered by extensionists could also help farmers to correctly identify pests and use a control method only when the pest is present, thereby reducing untargeted use [36]. Additionally, insecticide overuse by untrained farmers in the tropics can be a source of higher insecticide contamination that could also be avoided through better training [37]. Overall, the current pluralistic extension agencies need to better communicate and coordinate, both among themselves and with farmers, to synergistically improve extension services [31,32]. New learning tools, such as model-based games, might represent promising methods to address these issues [38,39]. Altogether, these examples illustrate the need for a better education of farmers and extensionists about insecticides (SDG 4).

\section{Lack of data and local funding}

The lack of reliable data in tropical compared to temperate regions impedes drawing strong conclusions about the level of contamination in tropical waters and soils $[24,40]$, and the impact on nontarget organisms [37]. This lack of data may be addressed through the development of harmonized protocols relevant across tropical areas, the training of local scientists and the access to sophisticated scientific equipment in some developing countries $[25,40,41]$. Local data is of particular importance for IPM because management solutions are developed on a case-by-case basis, with a redesign process accounting for the local context $[34,42]$. New methods of participatory data collection such as citizen science or living labs could also help to fill the gap. For example, the FAMEWS mobile phone app allows farmer to scout for fall armyworms (Spodoptera frugiperda) in their fields, and provides monitoring data and early warnings back to farmers [43]. Finally, funding is necessary to obtain these data, but is also necessary to sustain IPM programs in the long run to avoid chemical companies from filling the gap, leading to the abandonment of more sustainable control methods [34]. Increased coordination between extension services and combining several funding sources might provide more resilient funding (SDG 1 \& 17).

\section{Conclusion}

All the identified research topics and tropical drivers could be unified under the EfficiencySubstitution-Redesign framework for a conversion to a sustainable agriculture promoted by Pretty et al (2018) [ref. 42]. Indeed, the Efficiency stage can be linked with all the identified topics and with the necessity to perform research accounting for tropical climate and biodiversity, and the need to gather more data within tropical countries. The Substitution stage applies to bioinsecticide development and IPM, offering sustainable alternatives to synthetic insecticides, and highlighting the need for more data 
and a better education of farmers through the central role of extension services. Finally, the Redesign stage applies to all identified topics and insists on the case-by-case basis that requires more data under the specific local and wider tropical context.

In future research, some SDGs that we considered as not directly related to our identified topics could be further explored. For example, unequal gender (SDG5) access to extension service occurs [44] and should be taken into account by promoting interdisciplinary research necessary to attain sustainability [45]. Additionally, new research topics such as nanoparticle insecticides are too recent to evaluate their impact on sustainability (e.g. long-term impact on the environment and health) but may be promising avenues for sustainable research on insecticides in the tropics $[46,47]$.

\section{Author Contribution Statement}

Quentin Struelens: Conceptualization, Methodology, Formal analysis, Investigation, Data Curation, Writing - Original Draft, Writing - Review \& Editing. Pierre Silvie: Conceptualization, Methodology, Investigation, Writing - Review \& Editing, Supervision.

\section{Declaration of Competing Interest}

The authors declare that they have no competing financial interests that could have influenced the work reported in this paper.

\section{Acknowledgements}

We are grateful to Pierre Martin for advices about the topic classification model calibration. Q.S. was funded by a doctoral grant from Doctoral School ED227, Ministère de la Recherche, at the Muséum national d'Histoire naturelle (Paris, France). Q.S. was also supported by the McKnight Foundation through grant 16-213 (LEGUMIP). 


\section{References}

1. Abate T, van Huis A, Ampofo JKO: Pest Management Strategies in Traditional Agriculture: An African Perspective. Annual Review of Entomology 2000, 45:631-659.

2. Morales H: Pest Management in Traditional Tropical Agroecosystems: Lessons for Pest Prevention Research and Extension. Integrated Pest Management Reviews 2002, 7:145-163.

3. Schreinemachers $P$, Tipraqsa $P$ : Agricultural pesticides and land use intensification in high, middle and low income countries. Food Policy 2012, 37:616-626.

4. Alavanja MC: Introduction: Pesticides use and exposure, extensive worldwide. Reviews on environmental health 2009, 24:303-310.

5. Stehle S, Schulz R: Agricultural insecticides threaten surface waters at the global scale. Proceedings of the National Academy of Sciences 2015, 112:5750-5755.

6. Stanley J, Preetha G: Pesticide Toxicity to Non-target Organisms. Springer Netherlands; 2016.

7. Hawkins NJ, Bass C, Dixon A, Neve P: The evolutionary origins of pesticide resistance: The evolutionary origins of pesticide resistance. Biological Reviews 2019, 94:135-155.

8. Sachs J, Schmidt-Traub G, Kroll C, Lafortune G, Fuller G: Sustainable development report 2019. Bertelsmann Stiftung and Sustainable Development Solutions Network (SDSN): New York, NY, USA 2019,

9. Carvalho FP: Pesticides, environment, and food safety. Food and Energy Security 2017, 6:48-60.

10. Sanchez-Hernandez JC (Ed): Bioremediation of agricultural soils. CRC Press, Taylor \& Francis Group; 2019.

11. Kaushik G, Satya S, Naik SN: Food processing a tool to pesticide residue dissipation - A review. Food Research International 2009, 42:26-40.

12. Sánchez-Bayo F: Impacts of agricultural pesticides on terrestrial ecosystems. Ecological impacts of toxic chemicals Bentham Science Publishers Ltd, USA 2011,

13. Kogan M: Integrated Pest Management: Historical Perspectives and Contemporary Developments. Annual Review of Entomology 1998, 43:243-270.

14. Silvie PJ, Renou A, Vodounnon S, Bonni G, Adegnika MO, Héma O, Prudent P, Sorèze J, Ochou GO, Togola $\mathrm{M}$, et al.: Threshold-based interventions for cotton pest control in West Africa: What's up 10 years later? Crop Protection 2013, 43:157-165. 
15. Chandler D, Bailey AS, Tatchell GM, Davidson G, Greaves J, Grant WP: The development, regulation and use of biopesticides for integrated pest management. Philosophical Transactions of the Royal Society B: Biological Sciences 2011, 366:1987-1998.

16. Tambo JA: Recognizing farmer-generated innovations through contests: insights from four African countries. Food Security 2018, 10:1237-1250.

17. Isman MB: Botanical insecticides: for richer, for poorer. Pest Management Science 2008, 64:8-11.

18. Gurr GM, Wratten SD, Landis DA, You M: Habitat Management to Suppress Pest Populations: Progress and Prospects. Annual Review of Entomology 2017, 62:91-109.

19. Amoabeng BW, Johnson AC, Gurr GM: Natural enemy enhancement and botanical insecticide source: a review of dual use companion plants. Applied Entomology and Zoology 2019, 54:1-19.

20. Sanchez-Hernandez JC, Ro KS, Díaz FJ: Biochar and earthworms working in tandem: Research opportunities for soil bioremediation. Science of The Total Environment 2019, 688:574-583.

21. Karlsson S, Srebotnjak T, Gonzales P: Understanding the North-South knowledge divide and its implications for policy: a quantitative analysis of the generation of scientific knowledge in the environmental sciences. Environmental Science \& Policy 2007, 10:668-684.

22. Arbeli Z, Fuentes CL: Microbial degradation of pesticides in tropical soils. In Soil biology and agriculture in the tropics. . Springer; 2010:251-274.

23. Sanchez-Bayo F, Hyne RV: Comparison of environmental risks of pesticides between tropical and nontropical regions. Integrated Environmental Assessment and Management 2011, 7:577-586.

24. Stehle S, Bub S, Schulz R: Compilation and analysis of global surface water concentrations for individual insecticide compounds. Science of The Total Environment 2018, 639:516-525.

25. Daam MA, Chelinho S, Niemeyer JC, Owojori OJ, De Silva PMCS, Sousa JP, van Gestel CAM, Römbke J: Environmental risk assessment of pesticides in tropical terrestrial ecosystems: Test procedures, current status and future perspectives. Ecotoxicology and Environmental Safety 2019, 181:534-547.

26. Mina D, Struelens $Q$, Carpio $C$, Marco R, Rebai N, Rebaudo F, Dangles O: Lupin pest management in the ecuadorian Andes: current knowledge and perspectives. Outlooks on Pest Management 2017, 28:250-256.

27. Isman MB: Botanical Insecticides in the Twenty-First Century-Fulfilling Their Promise? Annual Review of Entomology 2020, 65.

28. Rico A, Waichman AV, Geber-Corrêa R, van den Brink PJ: Effects of malathion and carbendazim on Amazonian freshwater organisms: comparison of tropical and temperate species sensitivity distributions. Ecotoxicology 2011, 20:625-634.

29. Barbosa PRR, Oliveira MD, Barros EM, Michaud JP, Torres JB: Differential impacts of six insecticides on a mealybug and its coccinellid predator. Ecotoxicology and Environmental Safety 2018, 147:963971. 
30. Anderson JR, Feder G: Chapter 44 Agricultural Extension. In Handbook of Agricultural Economics. . Elsevier; 2007:2343-2378.

31. Benson A, Jafry T: The State of Agricultural Extension: An Overview and New Caveats for the Future. The Journal of Agricultural Education and Extension 2013, 19:381-393.

32. Leeuwis C: Communication for rural innovation: rethinking agricultural extension. John Wiley \& Sons; 2013.

33. Labarthe $P$, Laurent $C$ : Service economics and public policies for agricultural extension. Cahiers Agricultures 2011, 20:343-351.

34. Bottrell DG, Schoenly KG: Integrated pest management for resource-limited farmers: challenges for achieving ecological, social and economic sustainability. The Journal of Agricultural Science 2018, 156:408-426.

35. Parsa S, Morse S, Bonifacio A, Chancellor TCB, Condori B, Crespo-Pérez V, Hobbs SLA, Kroschel J, Ba $\mathrm{MN}$, Rebaudo $\mathrm{F}$, et al.: Obstacles to integrated pest management adoption in developing countries. Proceedings of the National Academy of Sciences 2014, 111:3889-3894.

36. Cock MJ: Funding taxonomic support to agriculture in developing countries. CABI Working Paper 2011

37. Daam MA, Van den Brink PJ: Implications of differences between temperate and tropical freshwater ecosystems for the ecological risk assessment of pesticides. Ecotoxicology 2010, 19:2437.

38. Duru M, Therond O, Martin G, Martin-Clouaire R, Magne M-A, Justes E, Journet E-P, Aubertot J-N, Savary S, Bergez J-E, et al.: How to implement biodiversity-based agriculture to enhance ecosystem services: a review. Agronomy for Sustainable Development 2015, 35:1259-1281.

39. Rebaudo F, Carpio C, Crespo-Pérez V, Herrera M, de Scurrah MM, Canto RC, Montañez AG, Bonifacio A, Mamani M, Saravia R, et al.: Agent-Based Models and Integrated Pest Management Diffusion in Small Scale Farmer Communities. In Integrated Pest Management. Edited by Peshin R, Pimentel D. Springer Netherlands; 2014:367-383.

40. Carriquiriborde P, Mirabella P, Waichman A, Solomon K, Van den Brink PJ, Maund S: Aquatic risk assessment of pesticides in Latin America: Aquatic Risk Assessment of Pesticides in Latin America. Integrated Environmental Assessment and Management 2014, 10:539-542.

41. Mohammed S, Lamoree M, Ansa-Asare OD, de Boer J: Review of the analysis of insecticide residues and their levels in different matrices in Ghana. Ecotoxicology and Environmental Safety 2019, 171:361-372.

42. Pretty J, Benton TG, Bharucha ZP, Dicks LV, Flora CB, Godfray HCJ, Goulson D, Hartley S, Lampkin N, Morris $C$, et al.: Global assessment of agricultural system redesign for sustainable intensification. Nature Sustainability 2018, 1:441-446. 
43. Feldmann F, Rieckmann U, Winter S: The spread of the fall armyworm Spodoptera frugiperda in Africa-What should be done next? Journal of Plant Diseases and Protection 2019, 126:97-101.

44. GFRAS: Fact Sheet on Extension Services. Position Paper: June 2012. 2012,

45. Irwin EG, Culligan PJ, Fischer-Kowalski M, Law KL, Murtugudde R, Pfirman S: Bridging barriers to advance global sustainability. Nature Sustainability 2018, 1:324-326.

46. Kumar S, Nehra M, Dilbaghi N, Marrazza G, Hassan AA, Kim K-H: Nano-based smart pesticide formulations: Emerging opportunities for agriculture. Journal of Controlled Release 2019, 294:131153.

47. Benelli G: Plant-mediated biosynthesis of nanoparticles as an emerging tool against mosquitoes of medical and veterinary importance: a review. Parasitology Research 2016, 115:23-34. 


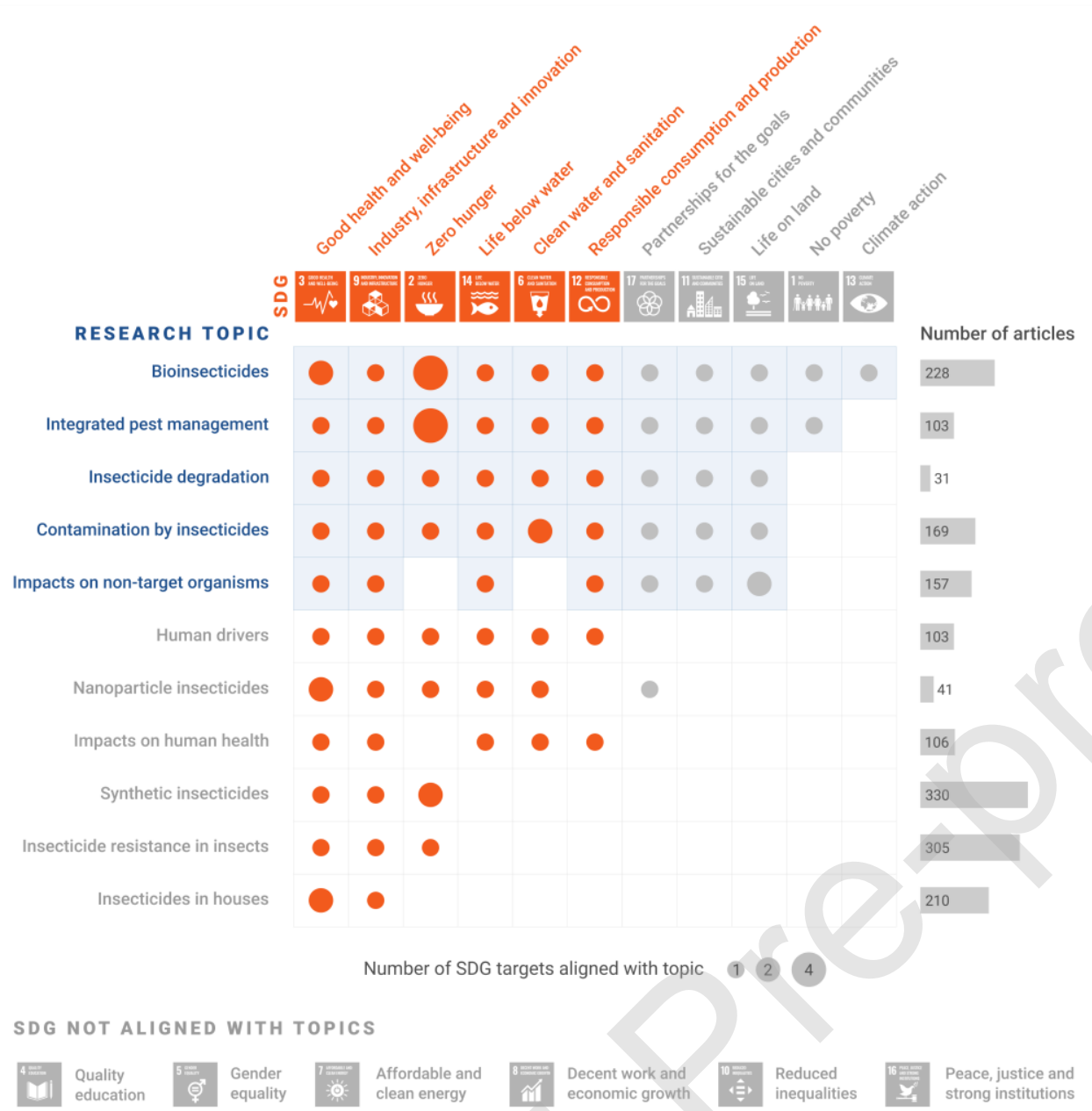

Figure 1 -Alignment of insecticide research topics with the specific targets of the Sustainable Development Goals (SDG) and the number of published articles for the period 2017-2019 in tropical countries. In the discussion, we mainly focus on the topics aligned with more than 7 targets (highlighted in blue). Circle diameter reflects the number of targets aligned with the research topic for each SDG. The SDG most aligned with research topics are highlighted in orange. Six SDG were not considered as directly aligned with research topics and are shown at the bottom part. Tropical countries are defined as having at least half of their land mass between the Tropics of Cancer and Capricorn. Only articles fulfilling the search criteria (TS = insecticide*) with accessible abstract and written in English were explored/read. The alignments between targets and research topics reflect the opinions of the authors. 
Table 1-Research topics (11) and subtopics (41) identified from our literature search and their alignments with specific targets from the Sustainable Development Goals (SDG). The list is based on the screening of the titles and abstracts of 439 articles randomly selected about insecticide research in tropical countries published between 2017 and 2019. The specific target numbers refer to the detailed list available at https://sustainabledevelopment.un.org/topics/sustainabledevelopmentgoals.

\begin{tabular}{|c|c|c|}
\hline Research topic & Subtopic & $\begin{array}{l}\text { Specific targets (of the } 17 \text { SDGs) } \\
\text { aligned with topic (combining } \\
\text { authors' opinions) }\end{array}$ \\
\hline \multirow[t]{6}{*}{ Insecticide resistance in insects } & & $2.3 ; 3.3 ; 9.5$ \\
\hline & Insecticide resistance mechanisms & \\
\hline & New technology in resistance detection & \\
\hline & Case study assessment of resistance & \\
\hline & Development of database on insect resistance & \\
\hline & Population genetic structure & 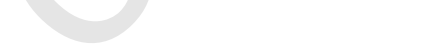 \\
\hline \multirow[t]{6}{*}{ Bioinsecticides } & & $\begin{array}{l}1.5 ; 2.1 ; 2.3 ; 2.4 ; 2.5 ; 3.3 ; 3.9 ; \\
6.3 ; 9.5 ; 11.4 ; 12.4 ; 13.3 ; 14.1 ; \\
15.9 ; 17.7\end{array}$ \\
\hline & $\begin{array}{l}\text { Development and synthesis of new bioinsecticide } \\
\text { and biorepellent }\end{array}$ & \\
\hline & $\begin{array}{l}\text { Case study assessment of bioinsecticide and } \\
\text { biorepellent }\end{array}$ & \\
\hline & Botanical extracts & \\
\hline & Entomopathogen microorganisms & \\
\hline & Plant elicitors & \\
\hline \multirow[t]{6}{*}{ Synthetic insecticides } & $\Delta$ & $2.3 ; 2.4 ; 3.3 ; 9.5$ \\
\hline & $\begin{array}{l}\text { Development and synthesis of new chemical } \\
\text { insecticides }\end{array}$ & \\
\hline & Case study assessment of chemical insecticides & \\
\hline & Chemically treated baits & \\
\hline & Adjuvant effect on insecticide effectiveness & \\
\hline & Mixture of insecticides & \\
\hline \multirow[t]{4}{*}{ Insecticides in houses } & F & $3.3 ; 3,9 ; 9.5$ \\
\hline & Treated nets and bed nets & \\
\hline & Wall lining & \\
\hline & Indoor residual spraying & \\
\hline \multirow[t]{5}{*}{ Contamination by insecticides } & & $\begin{array}{l}2.1 ; 3.9 ; 6.3 ; 6.6 ; 9.5 ; 11.4 ; 12.4 ; \\
14.1 ; 15.9 ; 17.7\end{array}$ \\
\hline & Water pollution by insecticides & \\
\hline & Soil pollution by insecticides & \\
\hline & $\begin{array}{l}\text { Development of biosensors and immunosensors for } \\
\text { insecticide detection }\end{array}$ & \\
\hline & Insecticide residues in food & \\
\hline \multirow[t]{2}{*}{$\begin{array}{l}\text { Insecticide degradation and } \\
\text { bioremediation }\end{array}$} & & $\begin{array}{l}2.1 ; 3.9 ; 6.6 ; 9.5 ; 11.4 ; 12.4 ; 14.1 ; \\
15.9 ; 17.7\end{array}$ \\
\hline & $\begin{array}{l}\text { Development of new technology for insecticide } \\
\text { removal }\end{array}$ & \\
\hline
\end{tabular}




\begin{tabular}{|c|c|c|}
\hline & Natural degradation rate of insecticides & \\
\hline \multirow[t]{7}{*}{ Integrated pest management } & & $\begin{array}{l}1.5 ; 2.1 ; 2.3 ; 2.4 ; 2.5 ; 3.9 ; 6.3 ; \\
9.5 ; 11.4 ; 12.4 ; 14.1 ; 15.9 ; 17.7\end{array}$ \\
\hline & IPM case studies & \\
\hline & Identification of new natural enemies & \\
\hline & Visual deterrent & \\
\hline & Combined effect of biocontrol agents & \\
\hline & Varietal selection of pest-resistant plants & \\
\hline & Pheromone and kairomone trap & \\
\hline \multirow[t]{4}{*}{$\begin{array}{l}\text { Human drivers impacting } \\
\text { insecticide effectiveness }\end{array}$} & & $2.3 ; 3.3 ; 6.3 ; 9.5 ; 12.4 ; 14.1$ \\
\hline & Access to pest control methods & \\
\hline & Incentives for insecticide use & ra \\
\hline & Policy and regulation & \\
\hline \multirow[t]{5}{*}{$\begin{array}{l}\text { Insecticide impacts on non-target } \\
\text { organisms }\end{array}$} & & $\begin{array}{l}3.9 ; 9.5 ; 11.4 ; 12.4 ; 14.1 ; 15.5 \\
15.9 ; 17.7\end{array}$ \\
\hline & Insecticide impacts on natural enemies & S \\
\hline & Insecticide impacts on organisms in water & 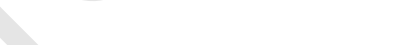 \\
\hline & Insecticide impacts on pollinators & 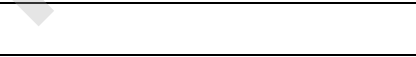 \\
\hline & Insecticide impacts on soil microorganisms & \\
\hline \multirow[t]{3}{*}{$\begin{array}{l}\text { Insecticide impacts on human } \\
\text { health }\end{array}$} & & $3.9 ; 6.3 ; 9.5 ; 12.4 ; 14.1$ \\
\hline & Insecticide poisoning & \\
\hline & Self-poisoning & \\
\hline \multirow[t]{3}{*}{ Nanoparticle insecticides } & 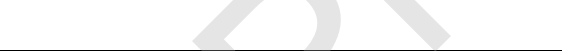 & $2.3 ; 3.3 ; 3.9 ; 6.3 ; 9.5 ; 14.1 ; 17.7$ \\
\hline & Nanoformulation & \\
\hline & Micro- and nanoencapsulation & \\
\hline
\end{tabular}

